\title{
Editorial
}

\section{A year to be remembered}

\author{
Marcel Bursztyn, Carlos Saito, Gabriela Litre, Patrícia Mesquita
}

doi:10.18472/SustDeb.v12n3.2021.41182

In 2020, in the editorial Annus Horribilis [SiD 11(1), we discussed the impact of the Covid-19 pandemic on all aspects of human life: health, economics, relationships politics-science, among others. Since science stepped up its efforts and developed vaccines in record time with great determination, hopes have been rekindled at the beginning of 2021. However, we end the year with unanswered questions.

If a significant percentage of the population refuses to be immunised and some governments do not consider the risks, how effective is vaccination?

Can risks be eliminated without ensuring the immunisation of the entire world population?

Economically more developed countries have acquired large vaccine doses in advance and stored them for future uses, reducing access to the poorest countries. What would be the way to strengthen countries' shared efforts for a globally immune population?

Can new variations of the coronavirus be prevented, and what is the relationship between these developments and the low vaccination rate of the population in some countries or regions?

What is the road towards social normality and economic activity at the pre-pandemic level?

And finally, how can we find a balance between respect for democracy for all and the right to freedom of choice when it comes to immunisation?

We have different answers to these questions, but the gap between reason and political decisionmaking is still vast. Countries with low economic growth, particularly in Africa, have insufficient access to vaccines. Like global climate issues, health challenges depend on universally-based solutions. The vaccine cannot be considered a commodity for share capital by the pharmaceutical industry or for economic power to guarantee future stocks. Well, not yet, anyway.

There are many lessons to be drawn from the human disaster this pandemic has caused. The global population needs mechanisms for action at the supra-national level. Overcoming economic, regional, social, racial and gender inequalities is crucial. Most vulnerable people are more than just part of the problem. They are the answer.

This vision of looking at the world from a pandemic perspective can also apply to other issues, like climate change, and we need to emphasise that.

This year was also marked by significant and extreme weather events (heatwaves, forest fires, heavy rains and floods). Progress was made at the 26th UN Conference of the Parties (COP-26) in Glasgow. It set out a higher commitment to reduce methane emissions (the global methane commitment ${ }^{1}$ ). Nevertheless, it has revealed extreme limitations since the pledges are not consistent, the objectives unclear, and the actual involvement of countries, lost in evasive proposals, especially in the short term. Brazilian participation at the Glasgow event was weak. The negligence and denial of governors 
have reached high levels, with the retreat of environmental policy and the loss of information on an increased Amazon deforestation.

While the balance is a concern, this year is not to be overlooked. Instead, it should remain a warning for risks and an opportunity for new arrangements and practices to be adopted in scientific research.

In science, along with the extraordinary efforts to develop vaccines and treatments, other fields have shown a tremendous ability to adapt to the new era of social distancing. In the socio-environmental domain, many suspended field activities have been replaced by remote interaction with local actors and public officials until the situation returns to normal. The study teams included researchers and community members. This results in advances in the processes of knowledge construction, with a higher tuning between the questions of the academy and the real demands of society at the local level. The learning process has been rich, and a new research model with interactive and participatory virtual activities has come to stay.

One of the biggest lessons of 2021 is to affirm the importance of systemic and collaborative thinking as the best way to address the global crisis. Countries need to work together and give greater emphasis to equity.

millions of people in vulnerable situations work in poor conditions, confirming the "uberization of work" is also negative effect of the Coronavirus pandemic. How many cases of indignity and injustice remain? How many people suffer from food insecurity and hunger? Where and how are millions of people working under unacceptable conditions to allow others to have the kind of food, products and opportunities they want?

Just as we cannot address climate change without global and urgent action, we cannot build the means to confront present challenges by relying on top-down global measures. Greater solidarity is needed in local communities through bottom-up coordinated network actions.

This issue features 13 articles in the Varia section and a list of reviewers that collaborated with our team to assess all the manuscripts received during this year. Our gratitude goes out to all of them.

This final edition of 2021 presents an initial set of articles that look at sustainability in the textile industry. Scafuto et al. talk about the relationship between project management and green innovation in sustainable fabric companies. Albuquerque et al. discuss the pre-consumption textile waste management in the clothing industry in Teresina/PI.

In a second block, Assunção et al. address a management plan based on integrated and sustainable agroecological production for medicinal plants in Rio de Janeiro. Távora et al. discuss perceptions of rice farmers in the Jequetepeque Valley, Peru, and demonstrate the importance of integrated actions to promote complex innovations in agriculture. Mesquita and Cavalcante present the role of the Cisterns Programs (water infrastructure) for family farmers in strengthening adaptive capacities to climate change in the Brazilian semi-arid. Still, in the semi-arid region, Tiburcio assesses the Great Drought in the northeast of Brazil (1877-1879) and concludes that nothing explains the impact of this drought and famine. Santos et al. present an additional article on the water crisis in Sao Paulo in 2013. They analyse elements that confirm that this is a socially constructed risk.

In a more managerial field, Braga and Fonseca discuss the fact that environmental policies improve reactively (and not proactively) and use the catastrophes of Mariana and Brumadinho as examples. Then, Back et al. analyse the São Paulo's master plan from the point of view of principles and guidelines for a compact city, sustainable adaptation and ecosystem-based adaptation, focusing on real dynamics and conflicts. Silva et al. make the link between environmental management at the municipal level and the regional conservation of the Eastern Amazon from the viewpoint of public officials in the State 
of Pará. Schossler et al. explore the lessons learned from a participatory methodology of ecosystem services assessment in the Uruguayan Pampa biome, the Tessa methodology (Toolkit for Ecosystem Service Site-Based Assessment). Bilyk et al. present the different approaches to introducing gender budgeting in countries as vital for ensuring sustainable development. And, finally, Campos et al. discuss the role of indigenous lands in the Amapá State for forest conservation.

We wish you all a good read and a healthy and peaceful New Year.

\section{NOTES:}

1 | https://ec.europa.eu/commission/presscorner/detail/en/statement_21_5766 